\title{
Application of 99mTc-3PRGD2 Imaging for Early Prediction of Pathological Response to Neoadjuvant Chemotherapy in Breast Tumors and Axillary Lymph Nodes
}

\section{Zhenying Chen}

First Affiliated Hospital of Fujian Medical University

\section{Fangmeng $\mathrm{Fu}$}

Xiehe Affiliated Hospital of Fujian Medical University

Junyu Lin

First Affiliated Hospital of Fujian Medical University

Chao Huang

First Affiliated Hospital of Fujian Medical University

\section{Shan Zheng}

First Affiliated Hospital of Fujian Medical University

\section{Chuan Wang}

Xiehe Affiliated Hospital of Fujian Medical University

Weibing Miao ( $\nabla$ miaoweibing@126.com )

First Affiliated Hospital of Fujian Medical University

\section{Original research}

Keywords: breast cancer, pathological complete response, 99mTc-3PRGD2, 18F-FDG, neoadjuvant chemotherapy

Posted Date: September 22nd, 2020

DOI: https://doi.org/10.21203/rs.3.rs-79314/v1

License: (우 This work is licensed under a Creative Commons Attribution 4.0 International License. Read Full License 


\section{Abstract}

Background and Purpose

Technetium $99 \mathrm{~m}$-dimeric cyclic RGD peptides with three polyethylene glycol spacers $\left({ }^{99 \mathrm{~m}} \mathrm{Tc}-3 \mathrm{PRGD} \mathrm{D}_{2}\right)$ had a good performance for diagnosing breast cancer. The prospective study was to assess the performance of ${ }^{99 m} \mathrm{Tc}-3 \mathrm{PRGD} \mathrm{D}_{2}$ tumor imaging for predicting pathological complete response ( $\mathrm{pCR}$ ) outcomes to neoadjuvant chemotherapy (NAC) in breast cancer patients.

Materials and Methods

Forty-one patients were examined using both ${ }^{99 \mathrm{~m}} \mathrm{Tc}-3 \mathrm{PRGD}{ }_{2}$ and ${ }^{18} \mathrm{~F}$-fluoro-deoxy-glucose $\left({ }^{18} \mathrm{~F}-\mathrm{FDG}\right)$ imaging before NAC (baseline), and after the first and fifth NAC cycle. The tumor-to-background (T/B) ratios for ${ }^{99 m} \mathrm{TC}^{3} 3 \mathrm{PRGD}_{2}$ imaging and the maximum standardized uptake values $\left(\mathrm{SUV}_{\max }\right)$ from the ${ }^{18} \mathrm{~F}-\mathrm{FDG}$ imaging in breast tumors and axillary lymph node (ALN) metastases were separately calculated and analyzed-based on receiver operating characteristic (ROC) analysis.

Results

Finally, pCR was achieved in 13 of 41 patients after NAC. The area under curve (AUC) of T/B changes $(\triangle T / B)$ in breast tumors for predicting pCR after first and fifth cycle were 0.827 and 0.687 , and 0.859 and 0.778 in ALN metastases, respectively. For $S U V_{\max }$ changes $\left(\triangle S U V_{\max }\right)$, the ROC-AUC were 0.859 and 0.713 , as well as 0.572 and 0.802 , respectively. In breast tumors, the AUCs of $\Delta T / B_{1}$ and $\Delta S U V_{\max 1}$ had no significant difference $(P>0.05)$. However, the AUC of $\Delta T / B_{1}$ was significantly higher than for $\triangle S U V_{\max 1}$ in ALN metastases $(Z=2.10, P=0.035)$. Additionally, the $T / B_{1}$ trends for breast tumor and ALN in pCR group were higher than for non-pCR group in HER2-positive patients $(P \otimes 0.05)$.

Conclusions

Compared with ${ }^{18} \mathrm{~F}-\mathrm{FDG}$ imaging, our study shows that use of ${ }^{99 \mathrm{~m}} \mathrm{Tc}-3 \mathrm{PRGD}$ imaging offered a similar level of predictive performance for breast cancer $\mathrm{PCR}$ to $\mathrm{NAC}$, and early $T / B_{1}$ trends of ALN showed an higher performance for predicting $\mathrm{PCR}$.

Trial Registration

ClinicalTrials.gov ID: NCT02742168.

\section{Introduction}

Breast cancer is one of the most common malignant tumors in females worldwide [1, 2]. Neoadjuvant chemotherapy (NAC) is an important therapeutic option for use with advanced stage patients and allows for more conservative surgeries to be performed and can facilitate the resection of tumors which are initially deemed inoperable $[3,4]$. Several studies have demonstrated that the responses to chemotherapy in breast 
cancer and metastatic axillary lymph nodes (ALN) are factors that apparently affect tumor prognosis, with especially pronounced associations in patients who achieve a pathological complete response (pCR) [5-7].

Previous studies used ${ }^{18} \mathrm{~F}$-fluoro-deoxy-glucose $\left({ }^{18} \mathrm{~F}\right.$-FDG) positron-emission-tomography/computedtomography (PET/CT) to monitor the therapy response during NAC [8-11]. However, the performance in predicting a PCR have to date been inconsistent among diverse breast cancer subtypes and between different monitoring time points. Study suggested that the relative changes of the maximum standardized uptake values (SUV $V_{\text {max }}$ ) after one cycle of NAC can accurately predict responsiveness in human epidermal growth factor receptor 2 (HER2) positive tumors [9], whereas a similar second study reported that PET/CT is useful for predicting PCR in estrogen receptor (ER) positive/HER2-negative and triple-negative tumors [10].

There were contradictory findings among different studies, thus, we aimed to explore another peptide probe to evaluate the pathological response of breast cancer. Integrin av $\beta 3$ is widely expressed in the cell-cell and cell-matrix, may have an essential function in contact that promotes tumor metastatic ability [12]. Tumor imaging study has shown that the HYNIC-3PEG4-E[c (RGDfK) $\left.{ }_{2}\right]\left(3 P R D_{2}\right)$ peptide specifically bound to tumor av $\beta 3$ and had a noticeable performance for diagnosing breast cancer when compared with ${ }^{18} \mathrm{~F}$-FDG imaging [13]. It is notable that ${ }^{99 \mathrm{~m}} \mathrm{Tc}-3 \mathrm{PRGD}$ e employs a lower radiation dose and more convenient labeling procedure than ${ }^{18} \mathrm{~F}-\mathrm{FDG}$; the ${ }^{99 \mathrm{~m}} \mathrm{Tc}-3 \mathrm{PRGD}{ }_{2}$ technique can be used to assesses tumor vascularization without access to PET equipment; even ${ }^{99 \mathrm{~m}} \mathrm{Tc}^{-} 3 \mathrm{PRGD}{ }_{2}$ can accurately recognized tumors with low ${ }^{18} \mathrm{~F}-\mathrm{FDG}$ uptake [14-18].

Several studies have reported that RGD peptides can be used to monitor early response of malignancies to chemoradiotherapy or to anti-angiogenesis therapy [19-22]. The changes of tumor integrin $a_{v} \beta_{3}$ expression and tumor to normal background ratio $(\mathrm{T} / \mathrm{B})$ on ${ }^{99 \mathrm{~m}} \mathrm{Tc}-3 \mathrm{PRGD}_{2}$ imaging in the squamous cell tumors significantly decreased in treatment group [22]. A study showed that ${ }^{99 \mathrm{~m}} \mathrm{Tc}-3 \mathrm{PRGD}$ imaging can monitor the early pathological response of primary breast tumors to NAC [23]. However, the definition of the pathological response of that study included minimal residual tumors, and it examined breast tumor pathological response only (i.e., no assessment of potential metastasis sites). Previous study showed that the ${ }^{99 \mathrm{~m}} \mathrm{Tc}-3 \mathrm{PRGD}{ }_{2}$ uptake rate was higher in HER2-positive breast patients than in luminal patients and triple-negative patients [13]. The combination of HER1/EGFR and HER2 is the most potent inducer of VEGF expression and tumor vascularity $[24,25]$. Therefore, we want to explore whether ${ }^{99 m} \mathrm{Tc}^{-3 P R G D}{ }_{2}$ imaging is a promising functional imaging modality for molecular phenotypes in breast cancer patients.

So, this study investigated the performance of ${ }^{99 \mathrm{~m}} \mathrm{Tc}-3 \mathrm{PRGD}{ }_{2}$ and ${ }^{18} \mathrm{~F}-\mathrm{FDG}$ imaging technologies in predicting pCR to NAC in both breast tumors and axillary nodes in advanced breast cancer patients. And the relationship between breast cancer subtype and pathological was also taken into consideration.

\section{Materials And Methods}


This study was approved by the institutional ethics committee of hospital. It has been registered online at $\mathrm{NIH}$ ClinicalTrails.gov (NCT 02742168). Written informed consent was obtained from all participants. The authors had full control of the data and information submitted for publication.

\section{Study participants}

This prospective study recruited 46 women who were first diagnosed with locally advanced stage II-III breast cancer from October 2015 to October 2018. The "gold standard" for diagnosis of the primary tumors and axillary lymph nodes were based on histopathological findings of fine needle biopsy (FNA) before treatment. The stage of cancer was determined by ${ }^{18} \mathrm{~F}-\mathrm{FDG} \mathrm{PET} / \mathrm{CT}$, ultrasound, MR, and/or whole-body bone imaging according to the TNM classification.

Exclusion criteria were: $\otimes 18$ year's old, pregnancy, and lactation period and the patients with distant metastatic lesions.

Five patients were excluded because two patients were diagnosed with distant metastases during NAC (a brain metastasis and a lumbar vertebrae metastasis diagnosed by MRI or PET/CT), and three patients missed followed up checks during NAC. Finally, forty-one patients were included in the final statistical analysis (mean age $61.50 \pm 7.84$ years, range from 25 to 65 ; mean weight $56.64 \pm 7.53 \mathrm{~kg}$, range from 40 to 69).

\section{Histopathological analysis and treatment}

Immunohistochemical (IHC) staining was used to determine the histological subtypes. ER or progesterone receptor (PR) status was defined as positive when the number of positive nuclei was $>1 \%$. HER2 expressed on the membrane was scored from 0 to 3 . Scores of $3+$ or $2+$ and fluorescence in situ hybridization positive detection was defined as HER2-positive. The breast cancer subtypes were categorized into luminal, HER2-positive and triple-negative.

All patients were treated with four cycles of NAC (epirubicin $90 \mathrm{mg} / \mathrm{m}^{2}$ on day 1 and cyclophosphamide 600 $\mathrm{mg} / \mathrm{m}^{2}$ on day 1 every 14 days) followed by four cycles of $\mathrm{T}$ (taxane $175 \mathrm{mg} / \mathrm{m}^{2}$ on day 1 every 21 days). In HER2-positive patients, trastuzumab was given with the last fourth cycle of taxane.

\section{Radiopharmaceutical preparation}

A $3 P R G D_{2}$ kit was supplied by the Medical Isotope Research Center of Peaking University. ${ }^{99 m}$ Tc-labled RGD peptide was a noninvasive imaging of integrin $\alpha_{v} \beta_{3}$ expression via SPECT and the preparation process of ${ }^{99 m} \mathrm{Tc}_{\mathrm{T}} 3 \mathrm{PRGD} \mathrm{D}_{2}$ have been fully characterized in previous studies $[13,26]$ The ${ }^{18} \mathrm{~F}-\mathrm{FDG}$ was purchased from Advance Medical Systems Limited, Nanjing, China.

\section{Imaging}

All patients underwent ${ }^{99 \mathrm{~m}} \mathrm{Tc}-3 \mathrm{PRGD}$ imaging and then ${ }^{18} \mathrm{~F}-\mathrm{FDG}$ imaging within three days. Each imaging series included three single-photon-emission-computed-tomography/computed-tomography (SPECT/CT) 
scans followed by three PET/CT scans. Note that baseline SPECT/CT 0 and PET/CT 0 imaging (first scan) were performed before the start of NAC, and after the first (second scan) and fifth (third scan) NAC cycles.

\section{9m Tc-3PRGD 2 Imaging}

For patients at SPECT/CT: after intravenous injection of $11.1 \mathrm{MBq} / \mathrm{kg}{ }^{99 \mathrm{~m}} \mathrm{Tc}-3 \mathrm{PRGD}$, whole-body planar $(10 \mathrm{~cm} / \mathrm{min})$ and SPECT/CT (30s/frame/6ロ) scans for thorax were performed using a double-headed $y$ camera equipped with low-energy high-resolution collimators (Infinia Hawkeye4, GE Healthcare). The matrix was $128 \otimes 128$ pixels, and the photo-peak was centered on $140 \mathrm{keV}$ with a $20 \%$ energy window.

\section{${ }^{18}$ F-FDG Imaging}

Patients were prepared via a 6-hour fasting period with blood glucose levels $<150 \mathrm{mg} / \mathrm{dl}$. An FDG dose of 170-230 MBq (0.1 mCi/kg) was given intravenously. PET/CT (Biography mCT (64), Siemens) scans were acquired at 60 minutes after ${ }^{18}$ F-FDG injection. A PET scan (2.00 min per bed position) was performed for each patient, and PET acquisition was followed by low-dose CT (3 mm slices). The standard supine $\mathrm{PET} / \mathrm{CT}$ was from the skull to the middle femur region.

\section{Imaging reading}

The three experienced nuclear medicine reading physicians were blinded to the pathological results, and could refer to other imaging results. A consensus decision was required for any discordant initial assessments. The readers evaluated the images visually for the focal tracer uptake compared with the uptake in surrounding normal tissue and the maximum radioactive counts of the primary breast tumors and prominent ALNs were measured in the two imaging modalities. If the patient without visible lymph node trace uptake for both of the imaging modalities at baseline would not undergo the subsequent pathological response predicting analysis.

\section{9m Tc-3PRGD 2 imaging analysis}

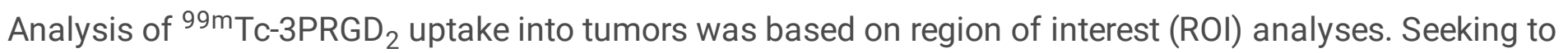
avoid nonspecific ${ }^{99} \mathrm{Tc}_{\mathrm{T}} \mathrm{PPRGD}_{2}$ uptake into benign lesions or normal breast tissue which were found in the previous studies [12], the blood pool of the aortic arch was used as a control for the primary tumor. For the controls in the for ALN image data, contralateral normal axillary areas were used. The mean counts for control regions of interest were measured and used as the background values for calculating the tumor-tobackground (T/B) ratios. Note that if an apparent tumor remission yielded no obvious tracer uptake, we analyzed the same region of interest location as in SPECT/CT 0 . We calculated T/B ratios for three SPECT/CT scans: $T / B_{0}, T / B_{1}$, and $T / B_{2}$, with each $T / B$ ratio calculated as follow:

$\Delta T / B_{1}=\left(\left(T / B_{0}-T / B_{1}\right) / T / B_{0}\right) \times 100 \%$

$\Delta T / B_{2}=\left(\left(T / B_{0}-T / B_{2}\right) / T / B_{0}\right) \times 100 \%$ 


\section{${ }^{18}$ F-FDG imaging analysis}

Nuclear medicine physicians used a standard analytical pipeline identified the mostly focal ${ }^{18} \mathrm{~F}$-FDG uptake of tumors and ALN. The ROls were drawn manually in the primary tumors and ALNs and measured the $S U V_{\max }\left(S U V_{\max }, S U V_{\max 1}, S U V_{\max 2}\right)$ obtained by generating a 3D region of interest [21].

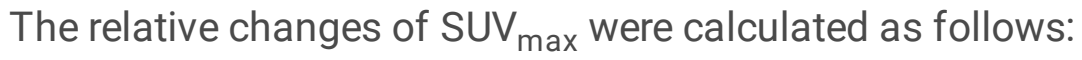

$\Delta S U V_{\max 1}=\left(\left(S U V_{\max 0^{-}} S U V_{\max 1}\right) / S U V_{\max 0}\right) \times 100 \%$

$\Delta S U V_{\max 2}=\left(\left(S U V_{\max } 0^{-S U V} V_{\max 2}\right) / S U V_{\max 0}\right) \times 100 \%$

\section{Response assessment}

Surgery with ALN dissection was performed after 8 cycles of NAC routinely. We defined pathological complete response ( $\mathrm{pCR}$ ) as the simultaneous absence of any residual invasive tumor cells from all of the breast and axillary node specimens.

\section{Statistical analysis}

Statistical analyses were performed using SPSS 24.0 software. Student's $t$-tests, Fisher's exact test, and binary logistic regression were used for analysis of parameters comparisons. The ROC curve analysis was used to evaluate the predictive performance of pathological responders vs. pathological non-responders. Z tests were used to compare the areas under curve (AUCs). $P<0.05$ was considered to be statistically significant.

\section{Results}

\section{Patient and treatment characteristics}

There were 35 total mastectomies and 6 nipple-sparing mastectomies. The forty-one breast tumors visualized in the ${ }^{99 \mathrm{~m}} \mathrm{TC}_{\mathrm{C}} 3 \mathrm{PRGD}{ }_{2}$ SPECT/CT 0 and ${ }^{18} \mathrm{~F}-\mathrm{FDG} \mathrm{PET} / \mathrm{CT}_{0}$ scans ranged in size from 1.75 to 8.0 cm. pCR was achieved in 13 of 41 (37.1\%) patients, which 9 of 17 HER2-positive patients, 3 of 18 luminal patients, and 1 of 6 triple-negative patients achieved pCR.

The basic characteristics and results of the univariate analyses of the 41 patients are listed in Table 1. Analysis of these data indicated that tumor size, tumor stage, and HER2-positive status were significantly associated with $\operatorname{pCR}(P=0.004,0.037$, and 0.014 , respectively $)$ in this cohort. Further, a logistic regression demonstrated that breast tumor size and HER2-positive status were predictive factors for $\mathrm{pCR}$, with odds ratio values (OR) of, respectively, $2.81(P=0.014,95 \% \mathrm{Cl} 1.237-6.388)$ and $0.129(P=0.020,95 \% \mathrm{Cl} 0.023-$ $0.722)$.

\section{Initial analyses with both imaging modalities}


There were 13 of 41 NAC pCR for primary breast tumors with ${ }^{99 m} \mathrm{Tc}^{2}-3 \mathrm{PRGD}{ }_{2}$ and ${ }^{18} \mathrm{~F}-\mathrm{FDG}$ uptake. Only one patient (HER2-positive) had no definite metastatic lymph node before treatment and finally reached pCR (Fig. 1). Forty of the patients were diagnosed with metastatic ALNs prior to NAC, and 12 of 40 patients with ALN metastases achieved pCR by ALN dissection. There were 2 of 3 HER2-positive patients with ALN

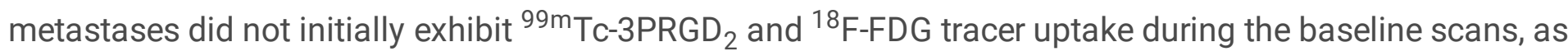
well as 10 of 37 patients with tracer uptake were eventually divided into pCR group.

\section{Predicting the PCR status based on tracers uptake trends in primary tumors}

The $\triangle T / B_{1}$ and $\triangle T / B_{2}$ values calculated from the ${ }^{99 m} T c-3 P R G D_{2}$ uptake for the primary breast tumor in pCR group were significantly higher than the corresponding values of the non-pCR group $(t=3.85, P<0.001$; $t=2.11, P=0.041$ ) (Table 2). The ROC-AUC of $\Delta \mathrm{T} / \mathrm{B}_{1}$ for predicting $\mathrm{pCR}$ status was 0.827 (95\% $\mathrm{Cl} 0.70-0.95$, $P=0.001$ ) (Fig. 2, a). However, the ROC-AUC of $\Delta \mathrm{T} / \mathrm{B}_{2}$ for predicting pCR was only 0.687 ( $95 \% \mathrm{Cl} 0.50-0.88$, $P=0.057$ ) (Fig. 2,a). Consistently, the $\Delta S U V_{\max 1}$ values of the primary breast tumor in pCR group exceeded those of the non-pCR $(t=4.32, P<0.001)$ (Table 2), and $\Delta S U V_{\max 1}$ displayed an impressive predictive value, with a ROC-AUC of $0.859(95 \% \mathrm{Cl} 0.72-1.00, P<0.001)$ (Fig. 2, b). The ROC-AUC of $\Delta S U V_{\max 2}$ was 0.713 (95\% $\mathrm{Cl} 0.54-0.88, P=0.030)$ (Fig. 2, b).

\section{Predicting the PCR status based on tracers uptake trends in ALN metastases}

$\triangle T / B_{1}$ and $\triangle T / B_{2}$ for $A L N$ metastases in pCR group were significantly higher than those in the non-pCR group ( $P=0.001$ and 0.025 , respectively) (Table 2). The ROC-AUCs of $\triangle \mathrm{T} / \mathrm{B}_{1}$ and $\triangle \mathrm{T} / \mathrm{B}_{2}$ in ALN metastases for predicting pCR were $0.859(95 \% \mathrm{Cl} 0.74-0.98, P=0.002)$ and $0.778(95 \% \mathrm{Cl} 0.63-0.93, P=0.014)$, respectively (Fig. 2, c). The $\triangle S U V_{\max 2}$ values of ALN metastases in pCR group were significantly higher than those of the non-pCR group $(P=0.005)$ (Table 2), and ROC analysis showed that the AUCs of $\triangle$ SUV $_{\max 1}$ and $\Delta \mathrm{SUV}_{\max 2}$ were $0.572(95 \% \mathrm{Cl} 0.33-0.81, P=0.523)$ and $0.802(95 \% \mathrm{Cl} 0.62-0.99, P=0.007)$, respectively(Fig. 2, d).

\section{Comparison early trends between the two imaging methods}

In the ROC analysis, AUCs of the $\triangle \mathrm{T} / \mathrm{B}_{1}$ on ${ }^{99 \mathrm{~m}} \mathrm{Tc} 3 \mathrm{PRGD} \mathrm{D}_{2}$ imaging (0.827) and the $\Delta \mathrm{SUV}_{\max 1}$ on ${ }^{18} \mathrm{~F}-\mathrm{FDG}$ imaging (0.859) for breast tumors showed comparable predictive value for $\mathrm{pCR}$ after one cycle $(\mathrm{Z}=0.33, P$ $=0.74)$. However, for ALN metastases, the AUC for the $\triangle T / B_{1}$ data from the ${ }^{99 m} T c-3 P R G D_{2}$ imaging data $(A U C=0.859)$ after first NAC cycle was greater than the AUC for the $\triangle S U V_{\max 1}$ data from ${ }^{18} \mathrm{~F}-\mathrm{FDG}$ imaging $(A \cup C=0.572)(Z=2.10, P=0.035)$.

\section{Early trends among breast cancer subtypes}

The detailed pathological response information of breast tumor subtypes are summarized in Fig. 1. We observed that among the HER2-positive patients the $\triangle T / B_{1}$ values of primary tumors and ALN metastases in pCR group were significantly higher than in non-pCR group (27.73®9.92 vs. $16.70 \rrbracket 10.51,36.80 \rrbracket 9.57$ vs. 17.82 8.60; all $P<0.05$ ) (Table 3). The result were observed among luminal patients, but it was notable that 
the trends (both $\Delta T / B_{1}$ and $\Delta \mathrm{SUV}_{\max 1}$ ) in primary breast cancer and $\triangle \mathrm{SUV}_{\max 1}$ in ALN metastases were additionally evident based on the SUV $\mathrm{max}_{\text {max }}$ data $(25.81 \rrbracket 7.38$ vs. $14.38 \llbracket 6.95,44.07 \llbracket 20.65$ vs. $16.38 \bigotimes 10.69$, 56.03ه11.61 vs. 34.46冈15.67; all $P<0.05$ ) (Table 3).

The Fig. 3 showed the images at three time-points scanning in a HER2-positive patient with pCR. Further, the Fig. 4 showed a non-pCR images in a luminal patient. Because only one patient achieved pathological complete responder in triple-negative, the subtype analysis was only performed in HER2-positive and luminal patients.

\section{Discussion}

The integrin $a_{v} \beta_{3}$ played important roles in tumor angiogenesis, invasion, and metastasis $[27,28]$. The integrin $\alpha_{v} \beta_{3}$ expression can be noninvasively observed in vivo by ${ }^{99 m} \mathrm{Tc}-3 P R G D_{2}$ imaging. This study showed that the primary tumors were found by two images, in addition, we found that some small metastatic lymph nodes exhibited no tracer uptake both in the initial scans of two modalities. Our previous work found that ${ }^{99 \mathrm{~m}} \mathrm{Tc}-3 \mathrm{PRGD}{ }_{2}$ imaging and ${ }^{18} \mathrm{~F}$-FDG imaging had a low-to-moderate sensitivity in small lymph nodes due to the low spatial resolution of SPECT and the size of lymph nodes [13]. Studies reported that micro-metastases with few malignant cells exhibit very weak tracer uptake levels and even need to be confirmed by pathology $[13,29]$.

A pCR in both primary breast tumor and axillary node shows a favorable outcome than breast pCR only [29, 30]. It bears emphasis that the definition used for PCR in our study was a lack of any invasive tumors in breasts and in lymph nodes. The pCR rate $(13 / 41 \varangle 31.7 \%)$ in this study was similar to that reported by previous studies $[8,9]$. The $\triangle T / B_{1}$ of primary tumors showed a ROC-AUC $(0.827)$ which was slightly lower than in a previous study (0.89) [23]. However, both that study and the present study found that the $\triangle T / B$ ratios for breast tumors in $\mathrm{pCR}$ group were higher than non-pCR group. Despite these similarities, there are some notable differences between the two studies, including the number of patients and the definition of pathological response, as well as the time interval for the chemotherapy. The proportion of patients of pCR in our study was only $31.7 \%$, as there were patients that presented with a small number of scattered tumor cells, thereby classifying them as non-pCR status.

${ }^{99 m} \mathrm{Tc}-3 \mathrm{PRGD} \mathrm{D}_{2}$ imaging performed similarly with the ${ }^{18} \mathrm{~F}-\mathrm{FDG}$ imaging for $\mathrm{pCR}$ prediction. When compared with ${ }^{18} \mathrm{~F}-\mathrm{FDG},{ }^{99 \mathrm{~m}} \mathrm{TC}-3 \mathrm{PRGD}{ }_{2}$ can be imaged even in practices without accessing to PET equipment. Moreover, the RGD peptide may offer biologically informative data relevant to antiangiogenic therapies and to anti-integrin $a_{v} \beta_{3}$ therapies. Previous studies have reported that micro-vessels are important factors that can affect breast cancer prognosis [31, 32]. The RGD peptide can be used to monitor the response of malignancies to antiangiogenic therapies [19-21]. A clinical trial showed that ${ }^{18} \mathrm{~F}$-galacto-RGD offered an advantage over ${ }^{18} \mathrm{~F}$-FDG PET for evaluating the anti-angiogenesis or anti-integrin $\mathrm{a}_{\mathrm{v}} \beta_{3}$ efficacy of cancer treatments [33]. At present, the targeted drugs for anti-angiogenesis therapy in breast cancer have been used in clinical research [19]. Imaging based on integrin $a_{v} \beta_{3}$ found that ${ }^{18}$ F-ALT-NOTA-PRGD 2 may predict a better response to apatinib anti-angiogenesis therapy in breast cancer [34]. A receptor imaging by combing 
diagnosis and monitoring drug response may be a valid instrument to select breast cancer patients who could benefit from targeted therapies [35].

Additionally, we found that the $\triangle T / B 1$ ratios of ALN metastases in pCR group were higher than in the nonpCR group; however, there were no statistically significant differences in the early FDG uptake changes $\left(\Delta S U V_{\max 1}\right)$. This can potentially be explained by the expected decrease in the integrin $a_{v} \beta_{3}$ expression level upon the initiation of tumor cell necrosis and/or apoptosis during NAC [22]. Integrin $\alpha_{v} \beta_{3}$ is widely expressed in the cell-cell and cell-matrix, may have an essential function in contact that promotes tumor metastatic ability [12]. Previous study reported that both the migration and metastasis capacity of tumor cells was significantly inhibited upon $a_{v}$ knockdown [36]. We found that the AUC of $\Delta T / B_{1}(0.859)$ in ALNs was greater than that of $\Delta \operatorname{SUV}_{\max 1}(0.572)$ for the early prediction of $\mathrm{pCR}(P=0.035)$. Xiaonan Jin et al. also reported that ${ }^{99 \mathrm{~m}} \mathrm{TC}-3 \mathrm{PRGD}{ }_{2}$ SPECT/CT imaging outperformed ${ }^{18} \mathrm{~F}$-FDG PET/CT in terms of higher specificity for the diagnosis of lung cancer lymph node metastasis [37]. It was thus notable that we were able to detect early ${ }^{99 m} \mathrm{Tc}-3 P R G D_{2}$ uptake changes in ALN metastases when monitoring the pCR. However, the aim was just to investigate the value of ${ }^{99 \mathrm{~m}} \mathrm{Tc}-3 \mathrm{PRGD}{ }_{2}$ imaging for predicting the breast tumors and ALNs pathological response but not to provide the monitor guidelines.

This study also indicated that HER2 status is associated with pCR: HER2-positive group obtained a higher pCR rate (9/13) than the HER2-negative group. Trastuzumab may increase the sensitivity of breast tumors to chemotherapy $[38,39]$. We found in the present study that the pCR group showed higher $\triangle T / B$ than the non-pCR group among HER2-positive patients. Our previous study demonstrated that the ${ }^{99 m} \mathrm{Tc}-3 \mathrm{PRGD}_{2}$ uptake rate of breast tumors was higher in HER2-positive patients than in luminal patients and triplenegative patients [23]. A clinical pathology study found a significant correlation between HER2 expression and microvessel density (MVD) in breast tumor specimens [40]. Another study reported a significant positive correlation between the RGD PET parameters and the HER2/CEP17 ratio in advanced invasive ductal carcinoma patients [41]. When compared with previous study [8], a similar result was observed in our study that ${ }^{18} \mathrm{~F}$-FDG PET/CT may predict pathological response in luminal tumors, but may be less accurate for HER2-positive tumors. As 5 triple-negative patients with non-pCR mentioned in the study, the chemoresistant may be predicted by imaging.

A limitation of our study was its limited number of patients, though the number was larger than previous study with ${ }^{99 m} \mathrm{Tc}-3 \mathrm{PRGD}_{2}$ imaging [23]. Further multi-center clinical studies with larger patient numbers would be informative: for example, the tumor subtype analyses and cut-off points could be given further consideration if the patient cohort size permitted in more hospital. Furthermore, different NAC regimes should be included in future comparative studies.

\section{Conclusion}

Our study shows that analysis of primary tumors and ALNs with either ${ }^{99 m} \mathrm{TC}-3 \mathrm{PRGD}$ imaging or ${ }^{18} \mathrm{~F}-\mathrm{FDG}$ imaging offers comparable performance levels for predicting pCR to NAC. Moreover, we found that 
monitoring of early changes in ALN metastases using ${ }^{99 m} \mathrm{Tc}-3 \mathrm{PRGD}_{2}$ imaging offered a more meaningful predictive information than ${ }^{18} \mathrm{~F}-\mathrm{FDG}$ imaging. ${ }^{99 \mathrm{~m}} \mathrm{TC}-3 \mathrm{PRGD} \mathrm{D}_{2}$ may be a promising functional imaging modality for prediction pathological response in HER2-positive patients.

\section{Abbreviations}

${ }^{99 m} \mathrm{Tc} 3 \mathrm{PRGD}_{2}$ : 99m-dimeric cyclic RGD peptides with three polyethylene glycol spacers; pCR: pathological complete response; NAC: neoadjuvant chemotherapy; ${ }^{18} \mathrm{~F}$-FDG: ${ }^{18} \mathrm{~F}$-fluoro-deoxy-glucose; T/B: tumor-tobackground; $S U V_{\text {max }}$ : maximum standardized uptake values; ALN: axillary lymph node; ROC: receiver operating characteristic; AUC: area under curve; PET/CT: positron-emission tomography/computedtomography; HER2: human epidermal growth factor receptor 2; ER: estrogen receptor; PR: progesterone receptor; SPECT/CT: single-photon-emission-computed-tomography/computed-tomography; ROI: region of interest; OR: odds ratio value

\section{Declarations}

\section{Conflicts of Interest}

All authors have no potential conflicts of interest to disclose.

\section{Acknowledgements}

The authors thank the Medical Isotope Research Center of Peaking University for the $3 \mathrm{PRGD}_{2}$ kit supply.

\section{Authors' contributions}

Study concepts/study design or data acquisition: all authors. Contribution to literature research: ZY, FF. Clinical patients recruiting: ZY, FF, JL, CW, WM. Image quality control, and data analysis: ZY, CH, SZ. Manuscript editing: ZY, WM. Manuscript drafting or manuscript revision for important intellectual content: all authors. Approval of final version of submitted manuscript: all authors. Agrees to ensure any questions related to the work are appropriately resolved: all authors.

\section{Funding}

This study was funded by the Sailing Fund of Fujian Medical University (2017XQ1099) and the National Natural Science Foundation of China (81971651).

\section{Availability of data and materials}

The datasets used and analyzed during the current study are available from the corresponding author on reasonable request.

\section{Ethics approval and consent to participate}


This study was approved by the institutional ethics committee of First Affiliated Hospital of Fujian Medical University. It has been registered online at NIH ClinicalTrails.gov (NCT 02742168).

\section{Consent for publication}

The consents to publish individual persons' data were obtained from participates.

\section{Competing interests}

All authors declare that they have no conflict of interest.

\section{Author details}

${ }^{1}$ Department of Nuclear Medicine, the First Affiliated Hospital of Fujian Medical University, 20 Chazhong Road, Taijiang District, Fuzhou 350005, P.R. China. ${ }^{2}$ Department of Breast Surgery, Xiehe Affiliated Hospital of Fujian Medical University, 29 Xinquan Road, Gulou District, Fuzhou 350001, P.R. China. ${ }^{3}$ Department of Breast Surgery, the First Affiliated Hospital of Fujian Medical University, 20 Chazhong Road, Taijiang District, Fuzhou 350005, P.R. China.

\section{References}

1. Oeffinger KC, Fontham ET, Etzioni R, Herzig A, Michaelson JS, Shih YC, et al. Breast Cancer Screening for Women at Average Risk: 2015 Guideline Update From the American Cancer Society. JAMA 2015;314:1599-1614.

2. DeSantis CE, Fedewa SA, Goding SA, Kramer JL, Smith RA, Jemal A. Breast cancer statistics, 2015:Convergence of incidence rates between black and white women. CA Cancer J Clin 2016;66:3142.

3. De luliis F, Salerno G, Corvino R, D'Aniello D, Cefalì K, Taglieri L, et al. Anthracycline-Free Neoadjuvant Chemotherapy Ensures Higher Rates of Pathologic Complete Response in Breast Cancer. Clin Breast Cancer 2016;17:34-40.

4. Dębska-Szmich S, Krakowska M, Czernek U, Habib-Lisik M, Zięba A, Potemski P. The role of preoperative systemic treatment in patients with breast cancer. Contemp Oncol (Pozn) 2016;20:93-101.

5. Esserman LJ, Berry DA, DeMichele A, Carey L, Davis SE, Buxton M, et al. Pathologic complete response predicts recurrence-free survival more effectively by cancer subset: results from the I-SPY 1 TRIALCALGB 150007/150012, ACRIN 6657. J Clin Oncol 2012;30:3242-3249.

6. Straver ME, Aukema TS, Olmos RA, Rutgers EJ, Gilhuijs KG, Schot ME, et al. Feasibility of FDG PET/CT to monitor the response of axillary lymph node metastases to neoadjuvant chemotherapy in breast cancer patients. Eur J Nucl Med Mol Imaging 2010; 37:1069-1076.

7. Cortazar P, Zhang L, Untch M, Mehta K, Costantino JP, Wolmark N, et al. Pathological complete response and long-term clinical benefit in breast cancer: the CTNeoBC pooled analysis. Lancet 2014;384:164-172. 
8. Koolen BB, Pengel KE, Wesseling J, Vogel WV, Vrancken PMJ, Vincent AD, et al. FDG PET/CT during neoadjuvant chemotherapy may predict response in ER-positive/HER2-negative and triple negative, but not in HER2-positive breast cancer. Breast 2013;22:691-697.

9. Humbert O, Berriolo-Riedinger A, Riedinger JM, Coudert B, Arnould L, Cochet A, et al. Changes in 18FFDG tumor metabolism after a first course of neoadjuvant chemotherapy in breast cancer: influence of tumor subtypes. Ann Oncol 2012;23:2572-2577.

10. Koolen BB, Pengel KE, Wesseling J, Vogel WV, Vrancken PMJ, Vincent AD, et al. Sequential (18)F-FDG PET/CT for early prediction of complete pathological response in breast and axilla during neoadjuvant chemotherapy. Eur J Nucl Med Mol Imaging 2014;41:32-40.

11. Connolly RM, Leal JP, Solnes L, Huang CY, et al.

TBCRC026: Phase II Trial Correlating Standardized Uptake Value With Pathologic CompleteResponse to Pertuzumab and Trastuzumab in Breast Cancer. J Clin Oncol 2019;37:714-722.

12. Wolfenson H, Iskratsch T, Sheetz MP. Early events in cell spreading as a model for quantitative analysis of biomechanical events. Biophys J 2014;107:2508-2514.

13. Chen Z, Fu F, Li F, Zhu Z, Yang Y, Chen X, et al. Comparison of [99mTc]3PRGD2Imaging and [18F]FDG $\mathrm{PET} / \mathrm{CT}$ in Breast Cancer and Expression of Integrin av $\beta 3$ in Breast Cancer Vascular Endothelial Cells. Mol Imaging Biol 2018;20:846-856.

14. Zhu Z, Miao W, Li Q, Dai H, Ma Q, Wang F, et al. 99mTc-3PRGD2 for integrin receptor imaging of lung cancer: a multicenter study. J Nucl Med 2012;53:716-722.

15. Zhou Y, Shao G, Liu S. Monitoring Breast Tumor Lung Metastasis by U-SPECT-II/CT with an Integrin $a(v) \beta(3)$-Targeted Radiotracer(99m)Tc-3P-RGD(2). Theranostics 2012;2:577-588.

16. Zhao D, Jin X, Li F, Liang J, Lin Y. Integrin avß3 imaging of radioactive iodine-refractory thyroid cancer using 99mTc-3PRGD2. J Nucl Med 2012;53:1872-1877.

17. Aide N, Briand M, Bohn P, Dutoit S, Lasnon C, Chasle J, et al. avß3 imaging can accurately distinguish between mature teratoma and necrosis in 18F-FDG-negative residual masses after treatment of non-seminomatous testicular cancer: a preclinical study. Eur J Nucl Med Mol Imagin 2011;38:323-333.

18. Li Y, Liu Z, Dong C, He P, Liu X, Zhu Z,et al. Noninvasive detection of human-induced pluripotent stem cell (hiPSC)-derived teratoma with an integrin-targeting agent 99mTc-3PRGD2. Mol Imaging Biol 2013;15:58-67.

19. Sun X, Ma T, Liu H, Yu X, Wu Y, Shi J, et al. Longitudinal monitoring of tumor antiangiogenic therapy with near-infrared fluorophore-labeled agents targeted to integrin av $\beta 3$ and vascular endothelial growth factor. Eur J Nucl Med Mol Imaging 2014;41:1428-1439.

20. Shi J, Jin Z, Liu X, Fan D, Sun Y, Zhao H, et al. PET imaging of neovascularization with (68)Ga-3PRGD2 for assessing tumor early response to Endostar antiangiogenic therapy. Mol Pharm 2014;11: 39153922.

21. Fakhrejahani E, Toi M. Antiangiogenesis therapy for breast cancer: an update and perspectives from clinical trials. Jpn J Clin Oncol 2014;44:197-207. 
22. Wu JG, Song SL, Zhou X, Wang F, Zhu YY, Xie L, et al. Biometabolic Distribution of 99mTc-3PRGD2 and Its Potential Value in Monitoring Chemotherapeutic Effects. Mol Imaging 2015;14:567-576.

23. Ji B, Chen B, Wang T, Song Y, Chen M, Ji T, et al. 99mTc-3PRGD2 SPECT to monitor early response to neoadjuvant chemotherapy in stage II and III breast cancer. Eur J Nucl Med Mol Imaging 2015;42:13621370.

24. Kumar R, Yarmand-Bagheri R. The role of HER2 in angiogenesis. Semin Oncol 2001;28:27-32.

25. Yen L, Benlimame N, Nie Z-R, Xiao D, Wang T, Al Moustafa A-E, et al. Differential regulation of tumor angiogenesis by distinct ErbB homo- and heterodimers. Mol Biol Cell 2002;13:4029-4044.

26. Miao W, Zheng S, Dai H, Wang F, Jin X, Zhu Z, et al. Comparison of 99mTc-3PRGD2 integrin receptor imaging with $99 \mathrm{mTc}$-MDP bone scan in diagnosis of bone metastasis in patients with lung cancer: a multicenter study. PLoS One 2014;9:e111221.

27. Seguin J, Nicolazzi C, Mignet N, Scherman D, Chabot GG. Vascular density and endothelial cell expression of integrin alpha v beta 3 and E-selectin in murine tumors. Tumor Biol 2012;33:1709-1717.

28. Gasparini G, Brooks PC, Biganzoli E, Vermeulen PB, Bonoldi E, Dirix LY, et al. Vascular integrin alpha(v)beta3: a new prognostic indicator in breast cancer. Clin Cancer Res 1998;4:2625-2634.

29. Straver ME, Aukema TS, Olmos RA, Rutgers EJ, Gilhuijs KG, Schot ME, et al. Feasibility of FDG $\mathrm{PET} / \mathrm{CT}$ to monitor the response of axillary lymph node metastases to neoadjuvant chemotherapy in breast cancer patients. Eur J Nucl Med Mol Imaging2010;37:1069-1076.

30. von Minckwitz G, Untch M, Blohmer JU, Costa SD, Eidtmann H, Fasching PA, et al. Definition and impact of pathologic complete response on prognosis after neoadjuvant chemotherapy in various intrinsic breast cancer subtypes. J Clin Oncol 2012;30:1796-1804.

31. Gasparini G, Brooks PC, Biganzoli E, Vermeulen PB, Bonoldi E, Dirix LY, et al. Vascular integrin alpha(v)beta3: a new prognostic indicator in breast cancer. Clin Cancer Res 1998;4:2625-2634.

32. Weidner N, Folkman J, Pozza F, Bevilacqua P, Allred EN, Moore DH, et al. Tumor angiogenesis: a new significant and independent prognostic indicator in early-stage breast carcinoma. J Natl Cancer Inst 1992;84:1875-1887.

33. Beer AJ, Lorenzen S, Metz S, Herrmann K, Watzlowik P, Wester HJ, et al. Comparison of integrin alphaVbeta3 expression and glucose metabolism in primary and metastatic lesions in cancer patients: a PET study using 18F-galacto-RGD and 18F-FDG. J Nucl Med 2008;49:22-29.

34. Li L, Ma L, Shang D, Liu Z, Yu Q, Wang S, et al. Pretreatment PET/CT imaging of angiogenesis based on 18F-RGD tracer uptake may predict antiangiogenic response. Eur J Nucl Med Mol Imaging 2019;46:940-947.

35. Salvatore B, Caprio MG, Hill BS, Sarnella A, Roviello GN, Zannetti A. Recent Advances in Nuclear Imaging of Receptor Expression to Guide Targeted Therapies in Breast Cancer. Cancers 2019;11:1614.

36. van den Hoogen C, van der Horst G, Cheung H, Buijs JT, Pelger RC, van der Pluijm G. Integrin av expression is required for the acquisition of a metastatic stem/progenitor cell phenotype in human prostate cancer. Am J Pathol 2011;179:2559-2568. 
37. Jin X, Liang N, Wang M, Meng Y, Jia B, Shi X, et al. Integrin Imaging with (99m)Tc-3PRGD2 SPECT/CT Shows High Specificity in the Diagnosis of Lymph Node Metastasis from Non-Small Cell Lung Cancer. Radiology 2016;281:958-966.

38. Coudert BP, Largillier R, Arnould L, Chollet P, Campone M, Coeffic D, et al. Multicenter phase II trial of neoadjuvant therapy with trastuzumab, docetaxel, and carboplatin for human epidermal growth factor receptor-2-overexpressing stage II or III breast cancer: results of the GETN(A)-1 trial. J Clin Oncol 2007;25:2678-2684.

39. von Minckwitz G, Untch M, Blohmer JU, Costa SD, Eidtmann H, Fasching PA, et al. Definition and impact of pathologic complete response on prognosis after neoadjuvant chemotherapy in various intrinsic breast cancer subtypes. J Clin Oncol 2012;30:1796-1804.

40. Vameşu S. Angiogenesis and c-erbB-2 (HER2/neu) overexpression status in primary breast cancer patients: an analysis of 158 needle core biopsies. Rom J Morphol Embryol 2007;48:121-129.

41. Yoon HJ, Kang KW, Chun IK, Cho N, Im SA, Jeong S, et al. Correlation of breast cancer subtypes, based on estrogen receptor, progesterone receptor, and HER2, with functional imaging parameters from $\triangle \mathrm{BGa}$

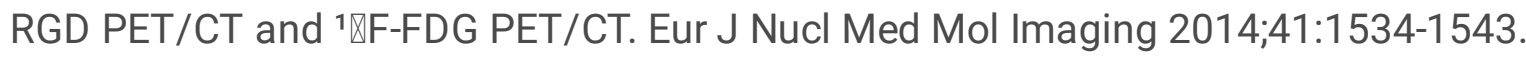

\section{Tables}

Table 1 Basic information and difference between pCR group and non-pCR group in 41 breast cancer patients 


\begin{tabular}{|c|c|c|c|}
\hline & $\begin{array}{l}\mathrm{pCR} \\
(\mathrm{n} \text { or Mean } \otimes \mathrm{SD})\end{array}$ & $\begin{array}{l}\text { non-pCR } \\
\text { (n or Mean } \otimes S D \text { ) }\end{array}$ & $P$ \\
\hline Age & $46.38 \llbracket 8.27$ & $43.75 \bigotimes 7.64$ & 0.323 \\
\hline Ki-67 & $53.08 \bowtie 20.57$ & $48.75 \rrbracket 20.98$ & 0.540 \\
\hline Tumor size & $2.68 \bowtie 0.74$ & $4.18 \rrbracket 1.67$ & $0.004^{*}$ \\
\hline \multicolumn{4}{|l|}{ Tumor stage } \\
\hline T1 & 6 & 7 & \\
\hline T2 & 7 & 13 & \\
\hline T3 & 0 & 6 & \\
\hline T4 & 0 & 2 & $0.037 *$ \\
\hline \multicolumn{4}{|c|}{ Lymph node stage } \\
\hline NO & 1 & 0 & \\
\hline $\mathrm{N} 1$ & 5 & 11 & \\
\hline N2 & 7 & 17 & \\
\hline N3 & 0 & 0 & 0.438 \\
\hline \multicolumn{4}{|l|}{ Clinical stage } \\
\hline I & 0 & 0 & \\
\hline II & 6 & 10 & \\
\hline III & 7 & 18 & 0.536 \\
\hline \multicolumn{4}{|l|}{ IV } \\
\hline \multicolumn{4}{|c|}{ Pathology subtype } \\
\hline HER2-positive & 9 & 8 & \\
\hline HER2-negative & 4 & 20 & $0.014^{\star}$ \\
\hline
\end{tabular}

* $P<0.05$

pCR pathological complete response, Ki-67 antigen Ki-67, HER2 human epidermal growth factor receptor 2, ER estrogen receptor

Table 2 The Relative Percentage Changes of T/B and SUV $\max$ for Primary Breast Tumors and ALN Metastases between pCR Group and non-pCR Group 


\begin{tabular}{|c|c|c|c|c|}
\hline & \multicolumn{2}{|c|}{ Pathological response } & \multirow[t]{2}{*}{$t$} & \multirow[t]{2}{*}{$P$} \\
\hline & pCR & non-pCR & & \\
\hline \multicolumn{5}{|l|}{ Primary tumor } \\
\hline \multicolumn{5}{|c|}{${ }^{99 m} \mathrm{Tc}_{\mathrm{T}} 3 \mathrm{PRGD} \mathrm{D}_{2}$ imaging } \\
\hline$\Delta \mathrm{T} / \mathrm{B}_{1}(\%)$ & $26.04 \llbracket 8.39$ & $14.64 \otimes 9.00$ & 3.85 & $<0.001^{*}$ \\
\hline$\Delta \mathrm{T} / \mathrm{B}_{2}(\%)$ & $72.87 \rrbracket 19.15$ & $55.69 \varangle 26.24$ & 2.11 & $0.041^{*}$ \\
\hline \multicolumn{5}{|c|}{${ }^{18} \mathrm{~F}-\mathrm{FDG}$ imaging } \\
\hline$\Delta S U V_{\max 1}(\%)$ & $56.08 \bowtie 16.37$ & $34.50 \otimes 14.16$ & 4.32 & $<0.001^{*}$ \\
\hline$\Delta S U V_{\max 2}(\%)$ & $75.64 \llbracket 12.58$ & $63.60 \otimes 19.81$ & 2.00 & 0.052 \\
\hline \multicolumn{5}{|l|}{ ALN } \\
\hline \multicolumn{5}{|c|}{${ }^{99 m} \mathrm{TC}-3 \mathrm{PRGD} \mathrm{D}_{2}$ imaging } \\
\hline$\Delta \mathrm{T} / \mathrm{B}_{1}(\%)$ & $36.12 \varangle 7.85$ & $20.32 \bigotimes 12.15$ & 3.63 & $0.001^{*}$ \\
\hline$\Delta \mathrm{T} / \mathrm{B}_{2}(\%)$ & $65.70 \otimes 7.25$ & $46.95 \nwarrow 23.39$ & 2.35 & $0.025^{\star}$ \\
\hline \multicolumn{5}{|c|}{${ }^{18} \mathrm{~F}-\mathrm{FDG}$ imaging } \\
\hline$\Delta S U V_{\max 1}(\%)$ & $47.35 \llbracket 31.10$ & $37.99 \otimes 19.95$ & 1.05 & 0.299 \\
\hline$\Delta \mathrm{SUV}_{\max 2}(\%)$ & $81.83 \rrbracket 16.01$ & $62.48 \otimes 16.80$ & 3.02 & $0.005^{\star}$ \\
\hline
\end{tabular}

*P<0.05

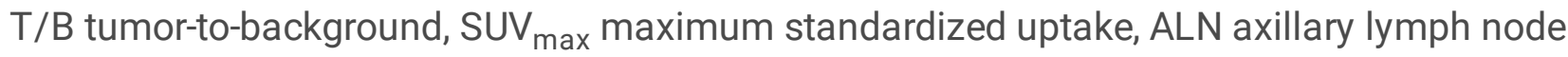

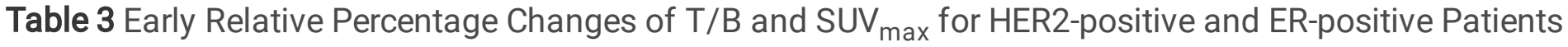
between pCR Group and non-pCR Group 


\begin{tabular}{|c|c|c|c|c|}
\hline & \multicolumn{2}{|c|}{ Pathological response } & \multirow[t]{2}{*}{$t$} & \multirow[t]{2}{*}{$P$} \\
\hline & $\mathrm{pCR}(\mathrm{n})$ & non-pCR (n) & & \\
\hline \multicolumn{5}{|l|}{ Primary tumor } \\
\hline \multicolumn{5}{|l|}{ HER2-positive } \\
\hline$\Delta \mathrm{T} / \mathrm{B}_{1}(\%)$ & $27.73 \llbracket 9.92(9)$ & $16.70 \otimes 10.51(8)$ & 2.23 & $0.042^{*}$ \\
\hline$\Delta \mathrm{SUV}_{\max 1}(\%)$ & $51.31 \otimes 9.46(9)$ & $39.10 \otimes 14.87(8)$ & 2.05 & 0.059 \\
\hline \multicolumn{5}{|l|}{ Luminal } \\
\hline$\Delta \mathrm{T} / \mathrm{B}_{1}(\%)$ & $25.81 \otimes 7.38(3)$ & $14.38 \otimes 6.95(15)$ & 2.58 & $0.020 *$ \\
\hline$\Delta \mathrm{SUV}_{\max 1}(\%)$ & $44.07 \rrbracket 20.65(3)$ & $16.38 ه 10.69(15)$ & 3.54 & $0.003^{*}$ \\
\hline \multicolumn{5}{|l|}{ Triple-negative } \\
\hline$\Delta \mathrm{T} / \mathrm{B}_{1}(\%)$ & $21.52(1)$ & $12.12 \bigotimes 12.96(5)$ & NA & NA \\
\hline$\Delta S U V_{\max 1}(\%)$ & 65.74 & $25.11 \otimes 18.10(5)$ & NA & NA \\
\hline \multicolumn{5}{|l|}{ ALN } \\
\hline \multicolumn{5}{|l|}{ HER2-positive } \\
\hline$\Delta \mathrm{T} / \mathrm{B}_{1}(\%)$ & $36.80 \llbracket 9.57(6)$ & $17.82 \bowtie 8.60(8)$ & 3.90 & $0.002^{*}$ \\
\hline$\Delta S U V_{\max 1}(\%)$ & $55.27 \bowtie 28.86(6)$ & $44.01 \otimes 14.21(8)$ & 0.967 & 0.353 \\
\hline \multicolumn{5}{|l|}{ Luminal } \\
\hline$\Delta \mathrm{T} / \mathrm{B}_{1}(\%)$ & $27.47 \llbracket 8.88(3)$ & 19.32ه9.32(14) & 1.38 & 0.187 \\
\hline$\Delta \mathrm{SUV}_{\max 1}(\%)$ & $56.03 \rrbracket 11.61(3)$ & $34.46 \bigotimes 15.67(14)$ & 2.23 & $0.042^{*}$ \\
\hline \multicolumn{5}{|l|}{ Triple-negative } \\
\hline$\Delta \mathrm{T} / \mathrm{B}_{1}(\%)$ & $38.87(1)$ & $18.79 \llbracket 22.25(5)$ & NA & NA \\
\hline$\Delta \mathrm{SUV}_{\max 1}(\%)$ & $25.34(1)$ & $34.30 \rrbracket 20.35(5)$ & NA & NA \\
\hline
\end{tabular}


$* P<0.05$

T/B tumor to background, SUV max maximum standardized uptake, ALN axillary lymph node, HER2 human epidermal growth factor receptor 2, ER estrogen receptor

\section{Figures}

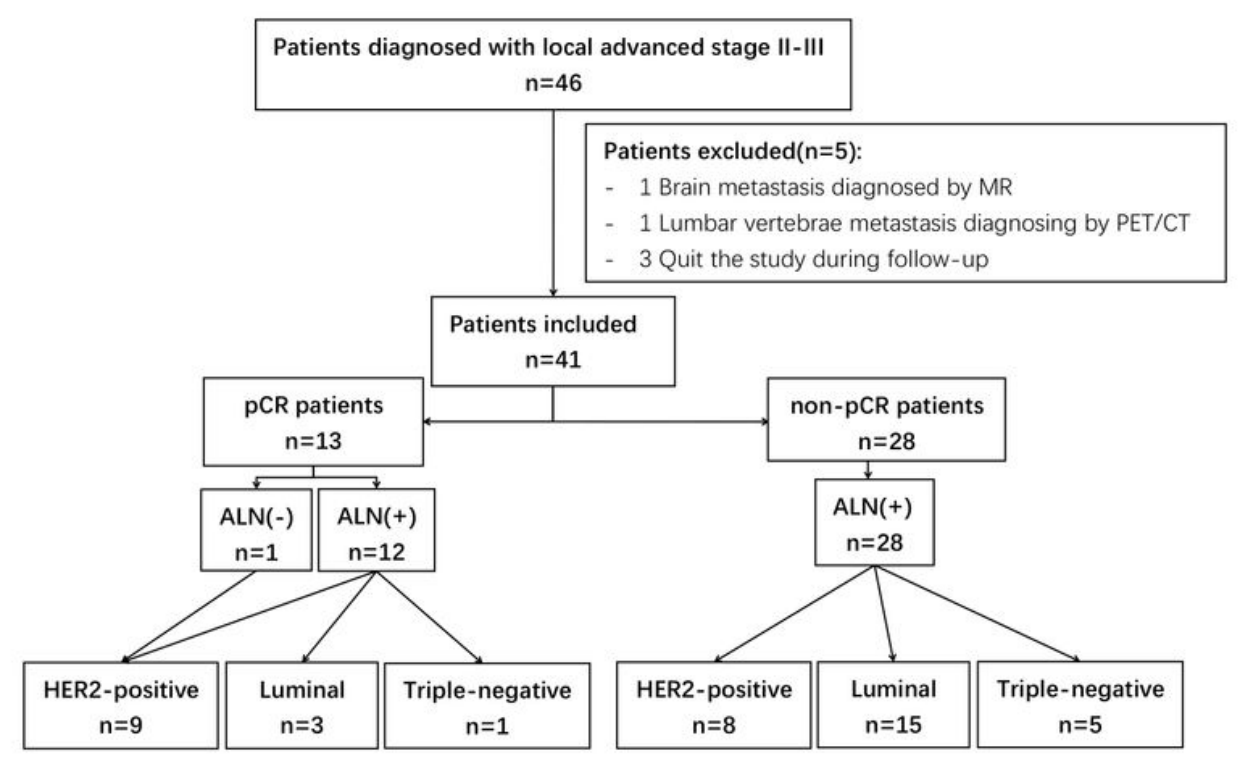

\section{Figure 1}

The pathological complete response (pCR) status to neoadjuvant chemotherapy (NAC) in 41 patients based on breast subtypes. 

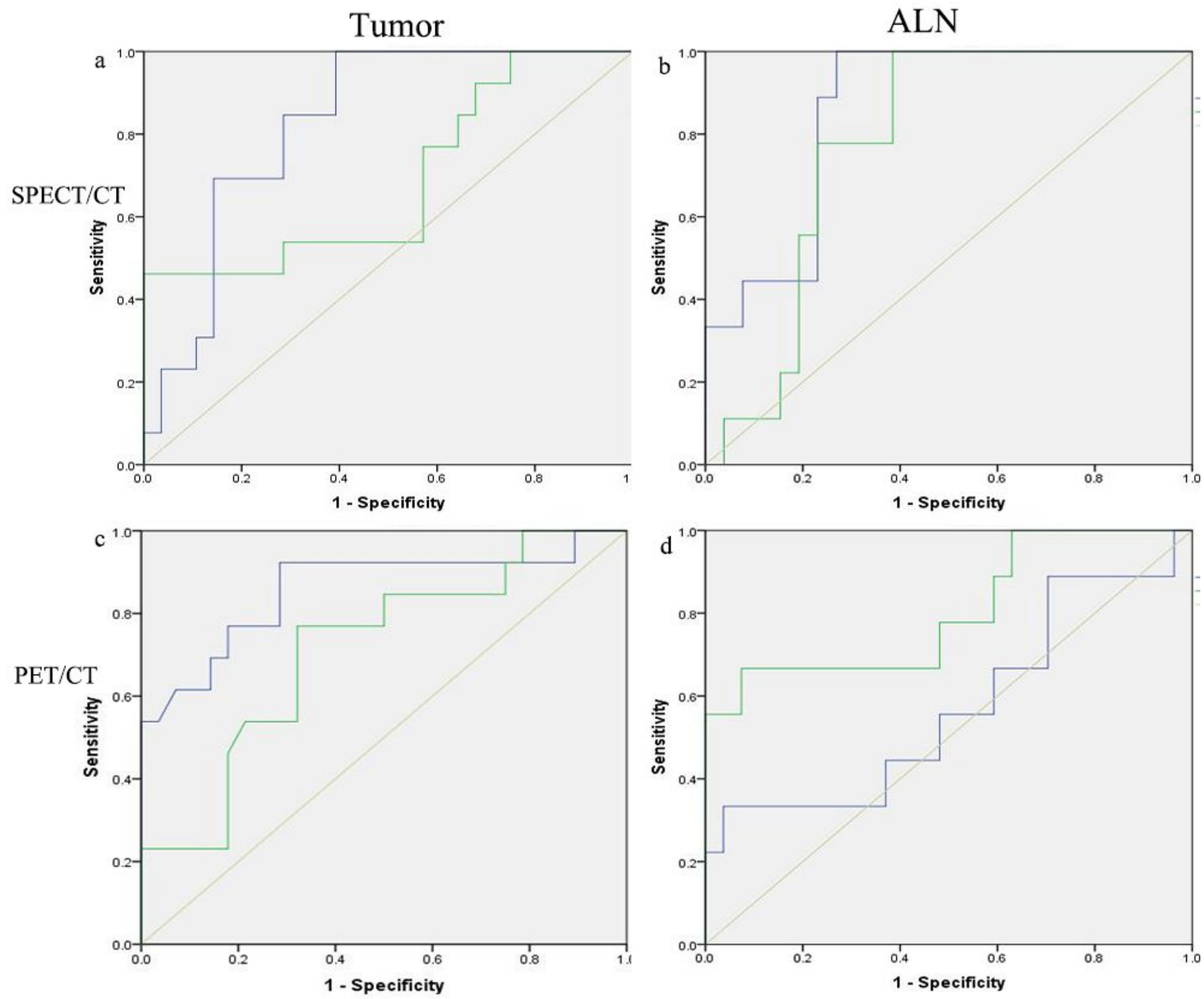

\section{Figure 2}

Comparison of receiver ROC-AUCs. The blue lines show the T/B or SUVmax changes between the baseline scan and second scan. And green lines show changes between the baseline scan and third scan. $a-b$ The ROC analysis of $\triangle T / B$ in primary tumors (a) and metastatic axillary lymph nodes (ALNs) (b) from 99mTc3PRGD2 imaging. The AUCs of $\triangle T / B$ for predicting pCR to NAC were 0.827 and 0.687 (tumors); and 0.859 and 0.778 (ALNs), respectively. $\mathrm{c}-\mathrm{d}$ The ROC analysis of $\triangle$ SUVmax changes on 18F-FDG imaging. AUCs of $\triangle S U V m a x$ for predicting pCR were 0.859 and 0.713 (c, tumors), 0.572 and 0.802 (d, ALNs), respectively. 


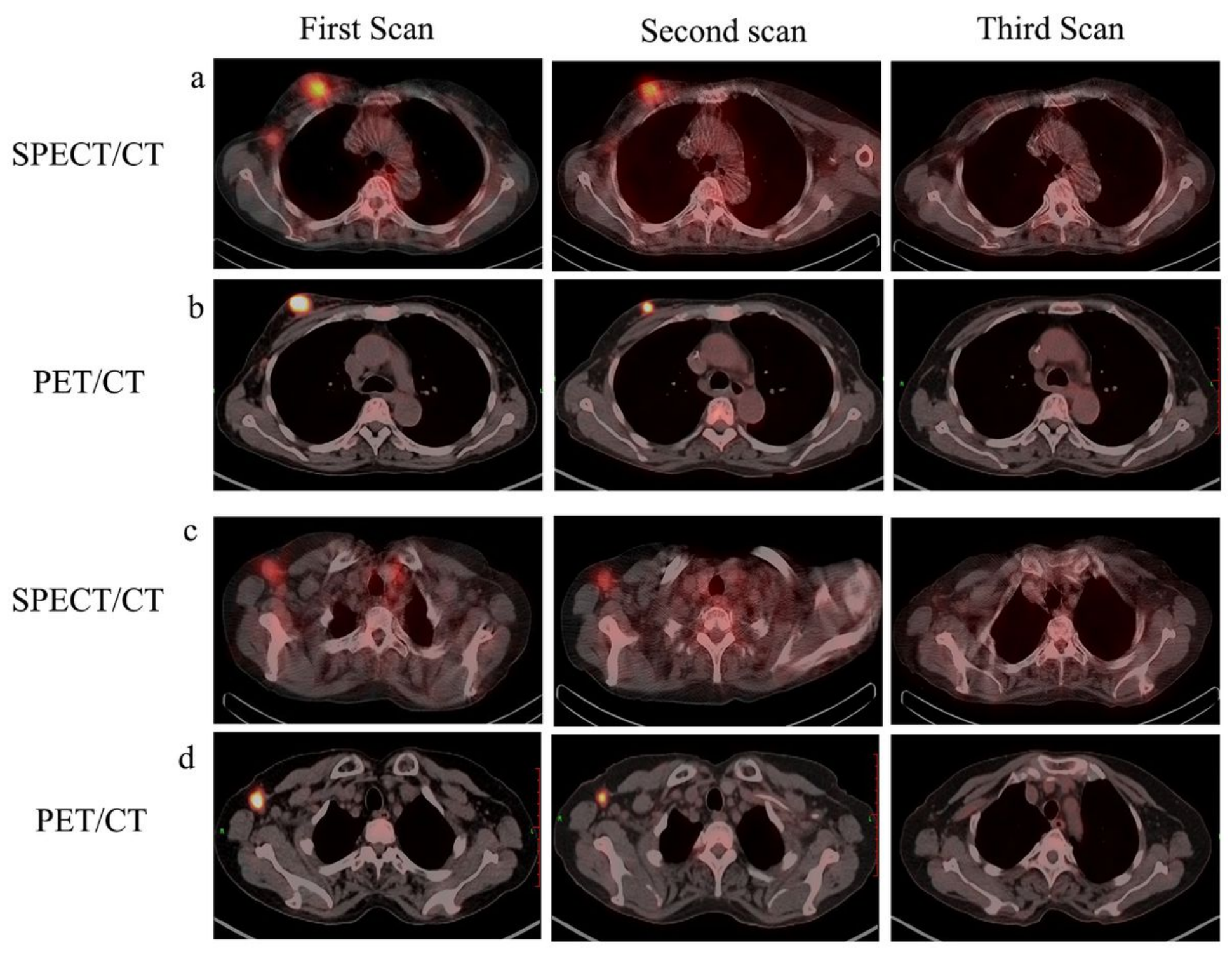

Figure 3

99mTc-3PRGD2 SPECT/CT and 18F-FDG PET/CT images. A 56-year-old woman diagnosed with right invasive ductal carcinoma and right ALN metastases (HER2-positive patient with pCR). The T/B or SUVmax changes and primary tumor size in second scan and/or third scan were markedly decreased compared with baseline scan during NAC. 
First Scan

a

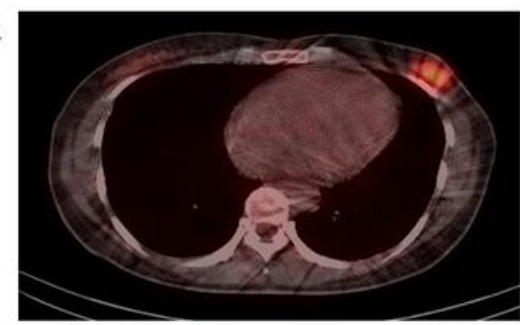

$\mathrm{b}$

$\mathrm{PET} / \mathrm{CT}$

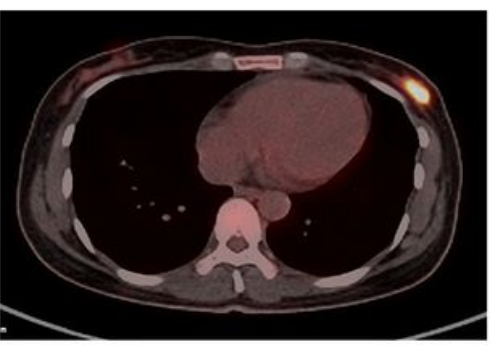

$\mathrm{C}$

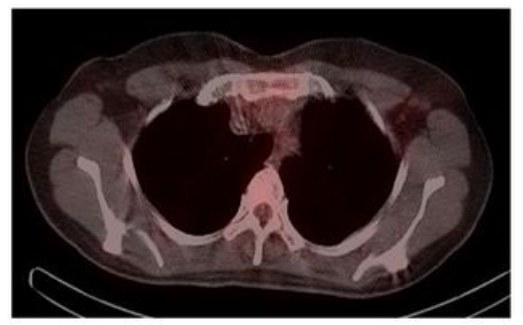

$\mathrm{d}$

$\mathrm{PET} / \mathrm{CT}$

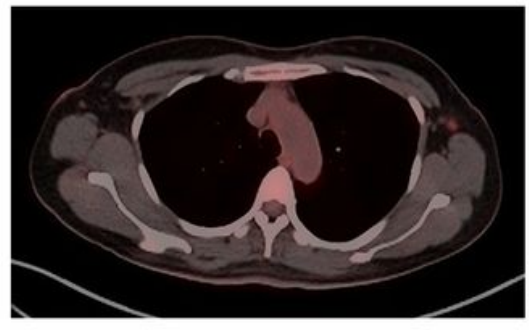

Second Scan
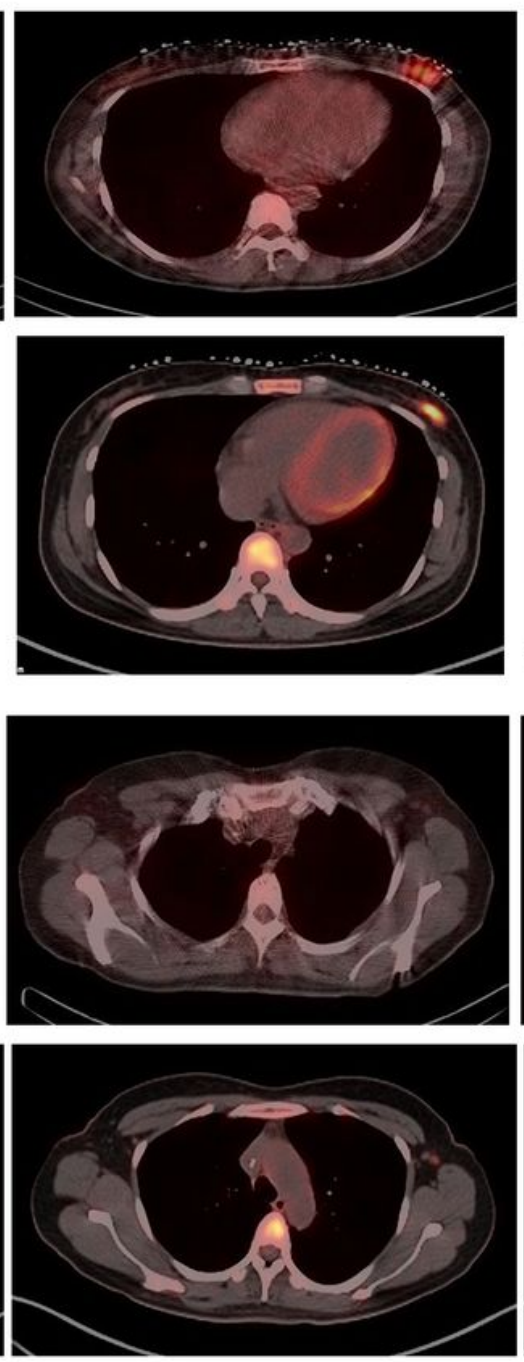

Third Scan
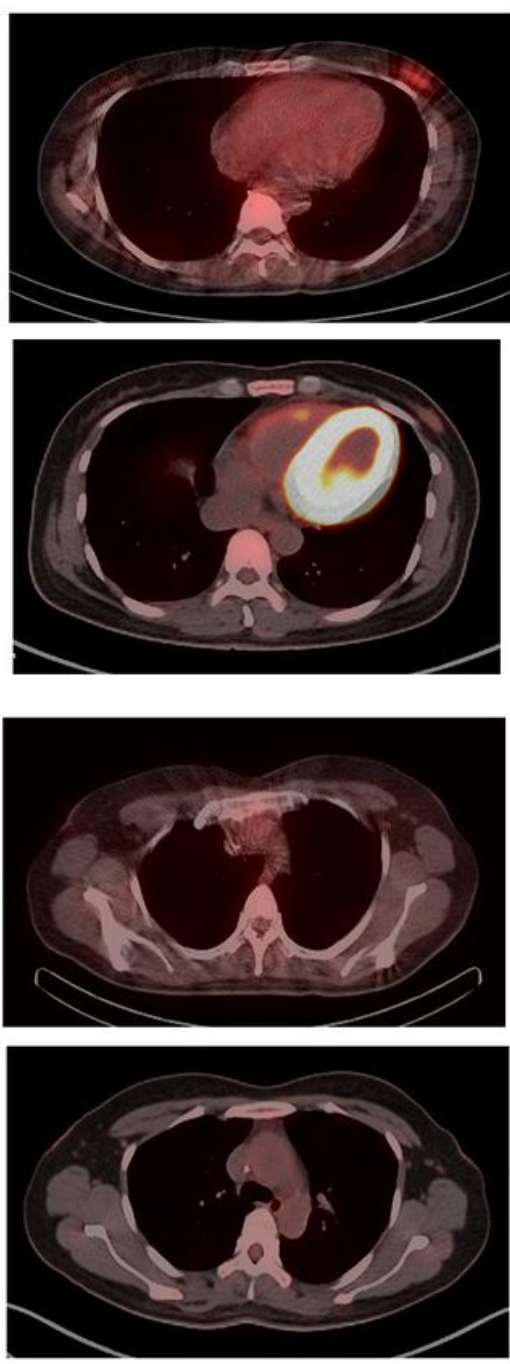

\section{Figure 4}

99mTc-3PRGD2 SPECT/CT and 18F-FDG PET/CT images. A 39-year-old woman diagnosed with left invasive ductal carcinoma and left ALN metastases (luminal patient with non-pCR). The T/B and SUVmax changes of primary tumor showed moderate decreased during NAC. Notably, the ALN showed slight increase uptake in two imaging modalities and the size was reduced inapparently compared with baseline scanning. 